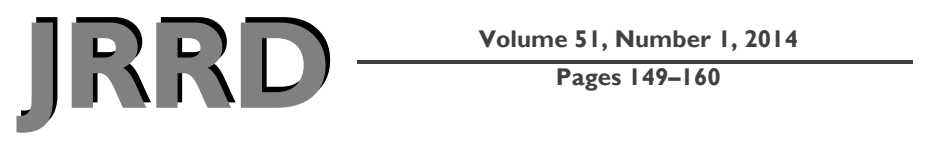

\title{
Comparison of Veteran experiences of low-cost, home-based diet and exercise interventions
}

\author{
Bree Holtz, PhD; ${ }^{1}$ Sarah L. Krein, PhD, RN; ${ }^{1-2}$ Douglas R. Bentley, MPH; ${ }^{1}$ Maria E. Hughes, MPT; $^{1}$ Nicholas $^{1}$ \\ D. Giardino, $\mathrm{PhD} ;^{3}$ Caroline R. Richardson, $\mathrm{MD}^{1,4^{*}}$ \\ ${ }^{1}$ Center for Clinical Management Research, Department of Veterans Affairs Ann Arbor Healthcare System, Ann Arbor, \\ MI; Departments of ${ }^{2}$ Internal Medicine, ${ }^{3}$ Psychiatry, and ${ }^{4}$ Family Medicine, University of Michigan, Ann Arbor, MI
}

\begin{abstract}
Obesity is a significant health problem among Veterans who receive care from the Department of Veterans Affairs, as it is for so many other Americans. Veterans from Operation Enduring Freedom (OEF) and Operation Iraqi Freedom (OIF) experience a myriad of chronic conditions, which can make it difficult to maintain a physically active lifestyle. This pilot study tested the feasibility and user satisfaction with three low-cost, home-based diet and exercise programs, as well as point-of-decision prompts among these Veterans. The three programs target mechanisms that have been shown to improve healthy behavior change, including (1) online mediated social support, (2) objective monitoring of physical activity, and (3) structured high-intensity workouts. This was a randomized crossover trial; each participant used two of the three programs, and all used the point-of-decision prompts. Our qualitative results identified five overall themes related to social support, objective monitoring, structured activity, awareness and understanding, and the point-of-decision prompts. In general, participants were satisfied with and lost weight with each of the interventions. This study demonstrated that these lowcost interventions could be successful with the OIF/OEF Veteran population. A larger and longer study is planned to further investigate the effectiveness of these interventions.
\end{abstract}

Key words: diet, exercise, lifestyle, obesity, objective monitoring, OIF/OEF, physical activity, qualitative, technology, Veterans.

\section{INTRODUCTION}

Obesity is a growing health problem in the United States, with almost 36 percent of American adults considered obese by body mass index (BMI) criteria in 2010 [1]. As in the general population, there is a high prevalence of obesity and overweight in Veterans [2-3]. This is especially true of Veterans who receive care from the Department of Veterans Affairs (VA) [4-5]. Veterans are more likely to be overweight or obese by BMI than non-Veterans, and Veterans who use VA health services are more likely to be overweight or obese than those who do not use VA services, even after adjusting for potential confounders such as age and sex [2]. Active Duty military personnel tend to be physically fit, yet many Veterans find it difficult to maintain an active lifestyle when they return to civilian life. Veterans from Operation Enduring Freedom (OEF) and Operation Iraqi Freedom (OIF) experience a high prevalence of chronic conditions, including chronic pain, mental illness, and substance abuse. Such chronic conditions make it even more difficult to maintain a physically active lifestyle [6].

\footnotetext{
Abbreviations: $\mathrm{BMI}=$ body mass index, $\mathrm{OEF}=$ Operation Enduring Freedom, OIF = Operation Iraqi Freedom, VA = Department of Veterans Affairs, VAMC = VA medical center.

*Address all correspondence to Caroline R. Richardson, MD; University of Michigan, Department of Family Medicine, 1018 Fuller St, Ann Arbor, MI 48104-1213; 734-9987120; fax: 734-998-7335. Email: caroli@umich.edu http://dx.doi.org/10.1682/JRRD.2013.04.0088
} 
Among OIF/OEF Veterans getting care at VA medical centers (VAMCs), the type of physical activities performed and level of intensity changes considerably postdeployment, shifting from vigorous exercise, such as running while deployed, to more moderate intensity exercise like walking [6]. These changes are in part driven by service-related medical and mental health problems.

The VA has been active in helping Veterans lose weight or maintain a healthy weight through the MOVE! program [7]. This program is a population-based approach that screens Veterans for obesity and provides them with evidence-based treatment options. These options include traditional weight loss techniques such as on-site support groups and self-management classes. These treatment options are based out of the regional VA facility, which can mean the Veterans may have to travel long distances to partake. Additionally, many of these programs occur on a weekly basis, making it extremely difficult for Veterans who are employed to participate. Therefore, it is important to explore other weight loss programs that are easy and inexpensively disseminated that can be done by the Veteran in his or her home.

In this pilot study, we tested feasibility and user satisfaction with three low-cost, home-based diet and exercise programs among OIF/OEF Veterans. Each of the programs employs a particular mechanism that has been shown previously to promote exercise and diet-related behavior change. These mechanisms include (1) online mediated social support, (2) objective monitoring of physical activity, and (3) structured high-intensity workouts. These three mechanisms were selected because there is evidence supporting efficacy in weight loss for each of them.

Evidence for improved weight loss from social support delivered over the Internet comes from a number of different studies. First, in a study of users of a weight loss intervention that included an online forum, Hwang et al. found that users were highly engaged in the online forum and reported receiving encouragement and motivation posts from other users through forums [8-9]. Another study by Johnson and Wardle showed that use of online forums was significantly associated with weight loss in women but not in men [10]. Richardson et al. showed that accessing online forum posts by other users increased program retention in an Internet-mediated walking program [11].

Support for the effectiveness of self-monitoring of diet and exercise as a strategy for weight loss is also well established. Traditionally, those trying to lose weight have been encouraged to keep a paper and pencil log of what they eat and how much they exercise. However, Web-based services can make diet and exercise logging easier, and inexpensive devices are now available that can objectively measure physical activity for users, increasing the accuracy of self-monitoring [12-16]. A study by Pellegrini et al. demonstrated short-term weight loss when using an objective physical activity monitoring device [17]. Furthermore, a meta-analysis of interventions that used pedometers to objectively track physical activity demonstrated that individuals had modest weight loss [18].

The final weight loss strategy targeted in this pilot study was structured high-intensity workouts. Such workouts are traditionally facility-based, but a number of commercially available programs use videos or DVDs to deliver such interventions remotely. Structured highintensity workouts involve short, high-intensity bursts of activity and periods of recovery. These workouts have been shown to improve both physical and mental health [19], including long-term improvements in glucose tolerance, bone health, and cardiovascular health [20]. However, concerns about low rates of adherence and increased risk of injury may limit the effectiveness of this strategy.

In addition to the technology-based intervention, all participants also received point-of-decision posters to hang in their homes. Past studies have demonstrated that these have had some success in behavior change [21]. Along with the evidence-based rationale for selecting the interventions, we purposely selected programs that are commercially available, easy to disseminate, and relatively inexpensive.

While past research has investigated similar types of programs and has found positive results, it was all conducted within a general and relatively healthy (i.e., overweight but no other comorbidities) population. Such interventions may not work as well in the OIF/OEF Veteran population because of service-related injuries and disability. Therefore, this pilot and feasibility study examined the perceptions of OIF/OEF Veterans using low-cost, home-based, technology-mediated interventions that leverage social support, objective physical activity monitoring, and structured high-intensity workouts to promote weight loss. This study sought to support further larger trials of these programs to help Veterans control weight gain and engage in healthier behaviors. 


\section{METHODS}

\section{Study Design}

This randomized crossover trial was conducted at the Ann Arbor VAMC in Ann Arbor, Michigan, from May 2011 to February 2012. A total of three interventions were tested, with each participant using two of the three interventions for 6 wk each. Before randomization, participants completed a telephone screening to establish eligibility. Individuals who met the inclusion criteria were then invited to the Ann Arbor VAMC for an enrollment session to learn more about the study, have their height and weight measurements recorded, and complete the baseline assessment. All methods were approved by the Ann Arbor VA Institutional Review Board before data collection, and all participants provided informed consent during the enrollment session. Participants were then randomly assigned to a sequence of two of the three interventions (Figure 1). There was equal allocation to all possible sequences of the interventions. Instructions and related equipment for the first intervention were also provided during the initial visit. After 6 wk of the first intervention, participants completed a postintervention interview, returned any equipment, and then received instructions and equipment to crossover to the second intervention. After 6 wk with the second intervention, the participants returned the equipment and participated in a final interview.

\section{Participants}

Potentially eligible participants were any OIF/OEF Veteran with a BMI of 30 or greater who had a primary care provider at the Ann Arbor VAMC. Participants were recruited through help of the OIF/OEF coordinators (social workers), who included information about the study in monthly newsletters (July through October 2011). Additionally, recruitment flyers were posted in several locations throughout the VAMC. Primary care providers were also given information about the study and could refer patients to the trial. Eligibility criteria included being a member of the OIF/OEF Veteran cohort (i.e., service in Afghanistan or Iraq), being able to walk 100 yd (self-reported), using a computer daily with highspeed internet access, and having a working DVD player. Veterans who were pregnant, had a medical condition that might make it dangerous or medically inappropriate to engage in a diet and exercise program, had been told by their doctor not to participant in a diet or exercise program, had heart disease, or had an eating disorder were excluded.

\section{Data Collection and Measures}

The initial screening assessment collected demographic data including height, weight, sex, age, race, ethnicity, education level, income, and current employment status. As part of the baseline assessment, participants answered questions regarding their military service, percentage of service-connected disability for VA healthcare services, and technology usage. The baseline assessment also included several measures to assess social support related to exercise and diet [22]. Additionally, participants were asked about their general health [23], pain [24], and depression [25]. The baseline assessment was conducted at the initial

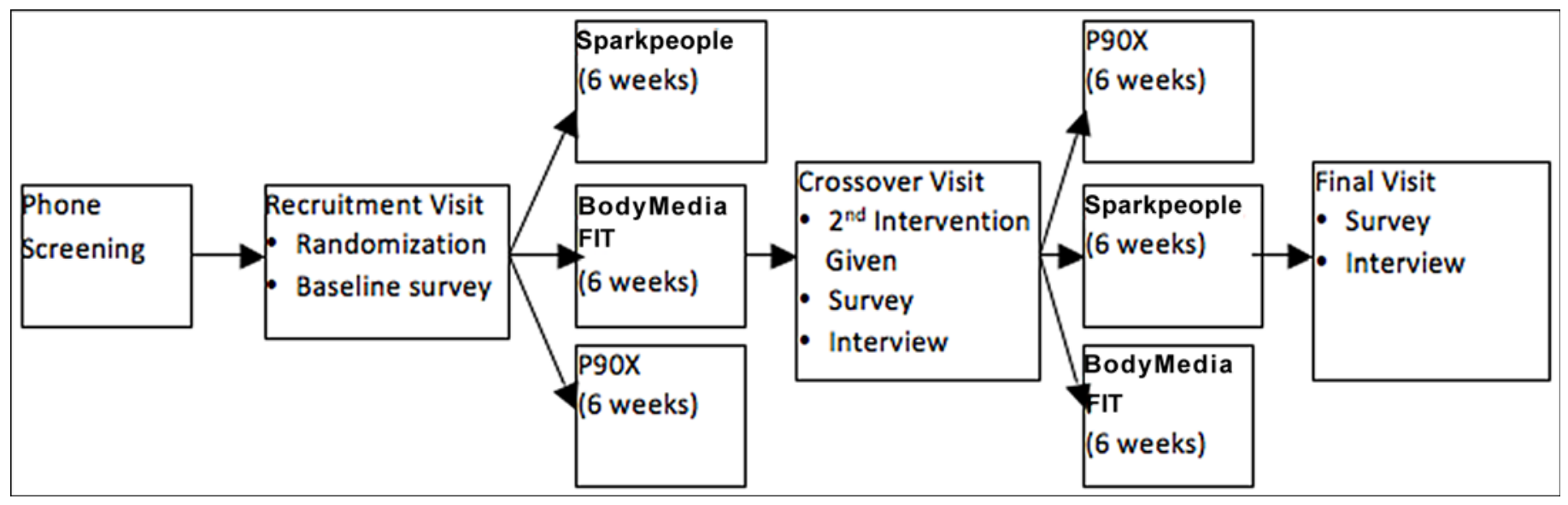

Figure 1.

Study design. 
enrollment session and interviews could be done either over the telephone or in person at the VAMC. The interviews were recorded and transcribed verbatim to allow for qualitative coding. Some examples of the interview questions can be found in Figure 2.

\section{Interventions}

The interventions used in this study are all commercially available and represent different components of technology-facilitated diet and exercise programs.

\section{Social Support}

There are many commercially available Internetmediated programs that leverage social support to improve individuals' diet and exercise behaviors. This study used a free and popular Web site called SparkPeople (www.sparkpeople.com, SparkPeople Inc; Cincinnati, Ohio), a publicly available diet and exercise-focused Web site that allows for social interactions between people on

1. Please describe how you used [intervention] during a typical (or the past) week.

2. Did you share the [intervention] information with others?

3. Was P90X motivating? Why/why not?

4. Did P90X increase awareness of your eating patterns? Why/why not?

5. Did P90X increase your awareness of your level of activity? Why/why not?

6. If we could continue to provide you with the BodyMedia FIT Device or [P90X (SparkPeople is free)], would you continue to use these programs on your own? Why/why not?

7. Was the level of exercise challenging enough; did you feel like you got a good workout? Why/why not?

8. What would you change about P90X? What would make it better?

9. Did any other aspects of your life change since using this program (for example: stress, sleep, chronic pain, social relationships, or anything else)?

10. Since you have had a chance to use both BodyMedia Fit and [SparkPeople P90X] (circle), we would now like you to compare them. Please tell us about features that you liked/disliked and why or if you preferred one over the other and why.

Figure 2.

Example interview questions. the site, creation or participation in groups or teams, and includes various online resources including food and fitness trackers, recipes, viewpoints, and ideas for new exercises. If the participant was randomized into this group, they were asked to join a discussion group, referred to as a team in SparkPeople, that was created and moderated by study staff specifically for participants in this study. Participants were provided with paper or email guides to help them log on to the Web site and with directions about accessing different parts of the Web site. In addition to joining the discussion group for the study, we asked that they use the food and fitness tracker (Figure 3) either from their computer or smartphone app and watch some online videos regarding use of the Web site.

\section{Objective Monitoring}

There are currently a large number of low-cost objective physical activity monitors marketed to the general public to support diet and exercise programs. Because the OIF/OEF population has a strong preference for resistance exercise and gym workouts, we used a device that could measure resistance exercise more accurately than a pedometer [2]. BodyMedia FIT (BodyMedia Inc; Pittsburgh, Pennsylvania) is a relatively low-cost option compared with hospital-based weight loss programs. Participants randomized to the BodyMedia FIT intervention were provided with the device that is worn on the arm (Figure 4). Because the device has metal contacts, anyone with a known metal allergy was excluded from randomization to this intervention. The device measures a person's exercise and sleep. Participants were asked to upload their data onto the BodyMedia FIT Web site (www.bodymedia.com) and to record their diet activity using the site or a smartphone app. In addition to the instructions that came with the device, participants were provided with a guide containing instructions about how to synchronize the device's data and log their daily food consumption.

\section{Structured High Intensity}

Participants randomized to the structured high-intensity intervention were provided with the P90X intervention (Beachbody LLC; Santa Monica, California). P90X is a low-cost, commercially available fitness program that is delivered on DVDs. Participants received the P90X DVDs (Figure 4), the P90X exercise and nutrition guides, and resistance bands. This program was selected because of its boot camp-like style and popularity with the study 
(a)

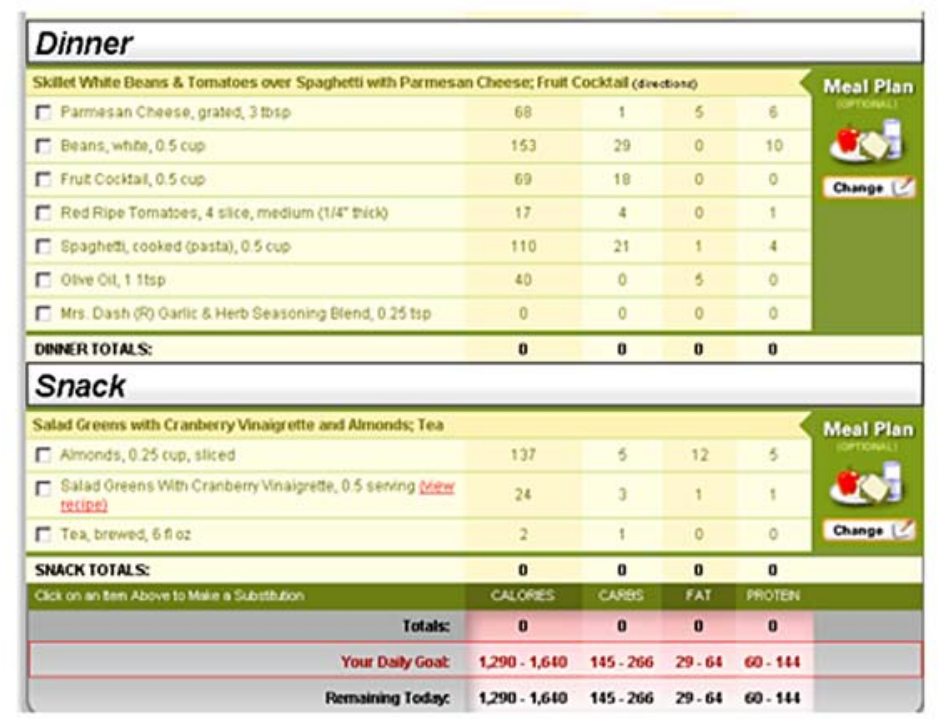

Figure 3.

(a) SparkPeople food tracker and (b) SparkPeople fitness tracker.

population. Additionally, one of the onscreen participants had a prosthetic leg, a disability common in Veterans. Participants were instructed to read the manuals and follow the program to the best of their ability but were also encouraged to modify the exercises as needed and to start slowly. We asked participants to join the online support group "Team Beachbody" managed by P90X. The participants were also provided with an additional guide (created by the research team) to help them get started using the program.

\section{Point-of-Decision Posters}

All participants were provided four point-of-decision posters (i.e., brief messages or reminders to encourage healthy behavior) and suggestions on where they should be located around their home. We included posters that encouraged the participants to take a walk to improve sleep, walk instead of drive, exercise while watching television, and have a healthy snack if they were hungry. These are very easy to distribute and, if successful, would be a cost-effective method to encourage behavior change.

\section{Data Analysis}

The baseline assessment data were analyzed using descriptive statistics, including means and standard deviations for continuous measures and frequencies and per- (b)

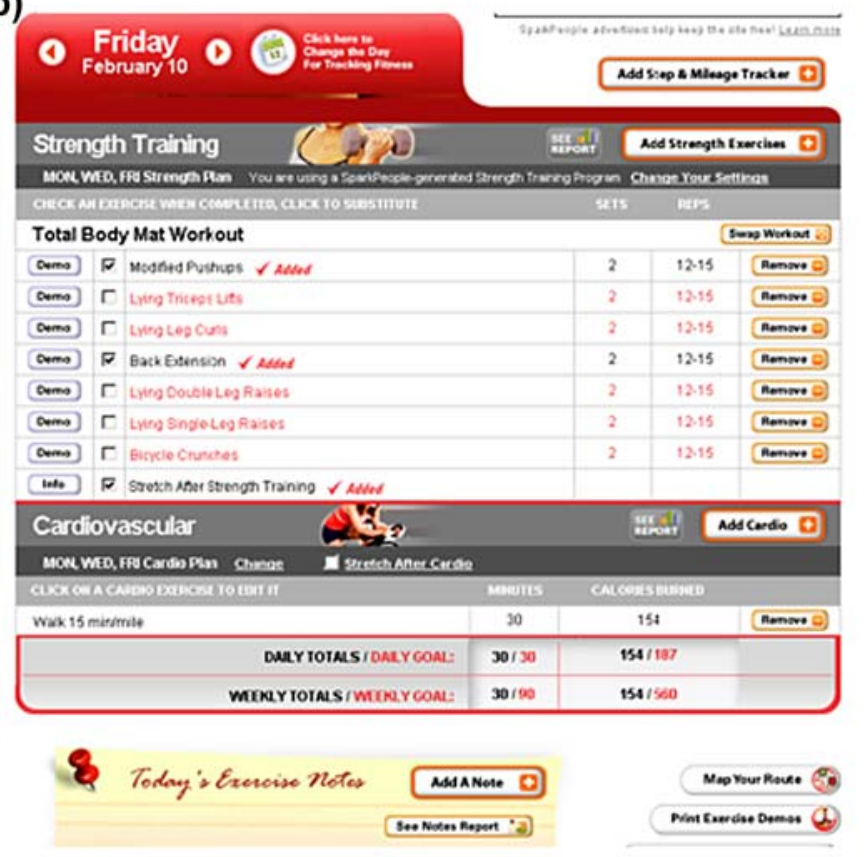

centages for binary variables. The interview data were analyzed using a grounded theory approach. First, several members of the research team read the transcripts and a series of open codes were developed based on concepts emerging from the data. Three members of the study team (BH, MEH, DRB) coded the interviews independently; any discrepancies were discussed and resolved. Coder reliability was established through assessment of percent agreement (>80\%) with the codes applied on a subset $(10 \%)$ of the interviews. These codes were applied to the transcripts and a thematic analysis was conducted to develop a list of common perceptions of the interventions.

\section{RESULTS}

\section{Quantitative Findings}

A total of 50 potential participants completed a telephone-screening interview to determine eligibility (Figure 5). Of these participants, 10 did not meet the inclusion criteria (4 had a BMI less than 30, 5 were not OIF/OEF Veterans, 1 did not have a VA primary care provider), 6 were not interested in participating, and 8 did not complete the telephone-screening interview. A total of 26 

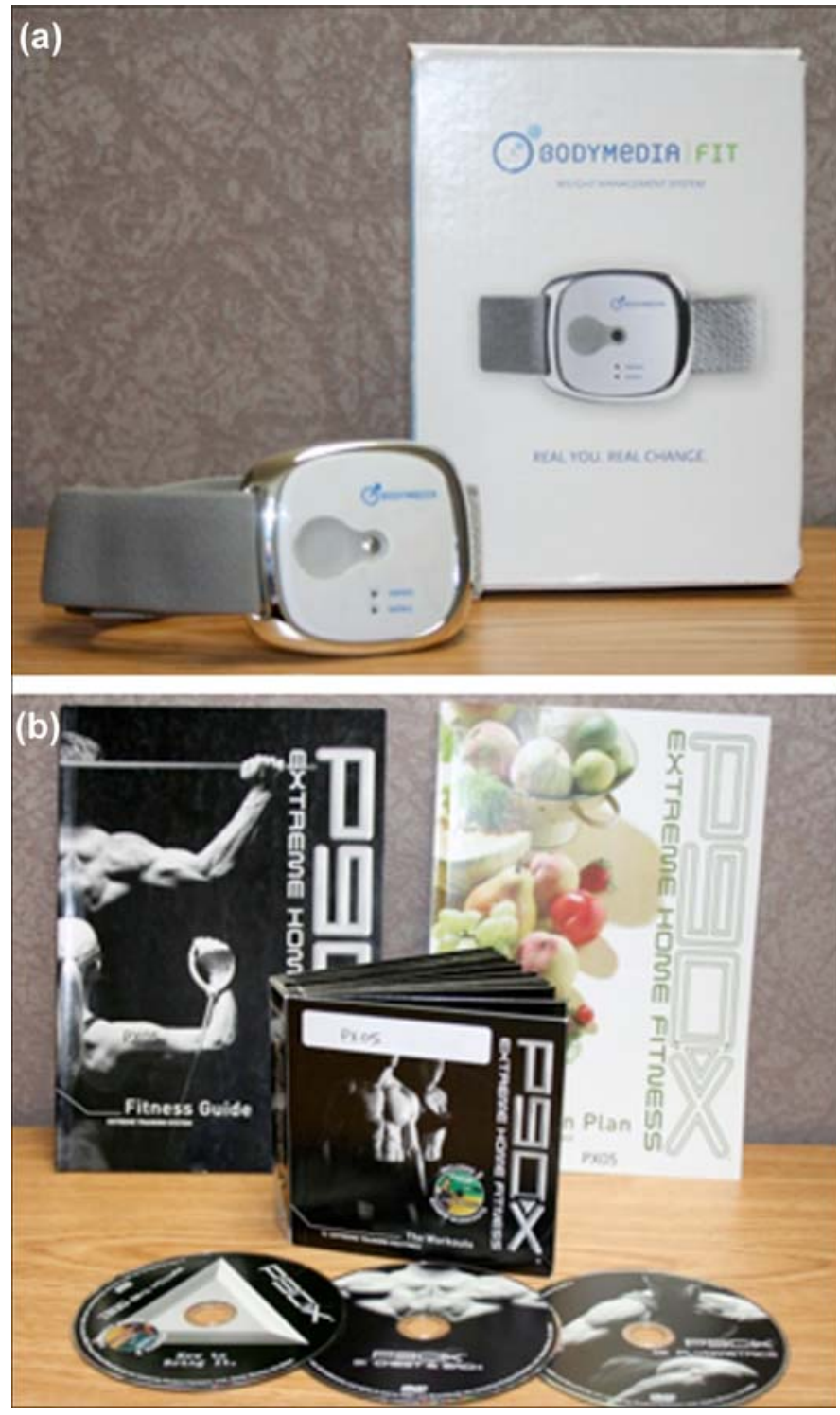

\section{Figure 4.}

(a) BodyMedia FIT (from Amazon) and (b) P90X (from P90X Web site).

participants were randomized into the first intervention series, and 6 of those were unavailable for follow-up (3 withdrew from the study and 3 were lost to follow-up). The remaining 20 participants started the second intervention arm and, of those, 19 completed the intervention, surveys, and interview. There were no significant baseline differences among the three study arms.

The average age of the participants was $37.4 \pm 12.3 \mathrm{yr}$ (mean \pm standard deviation), and the majority were male (66.6\%) and Caucasian (75\%) (Table). Over 50 percent

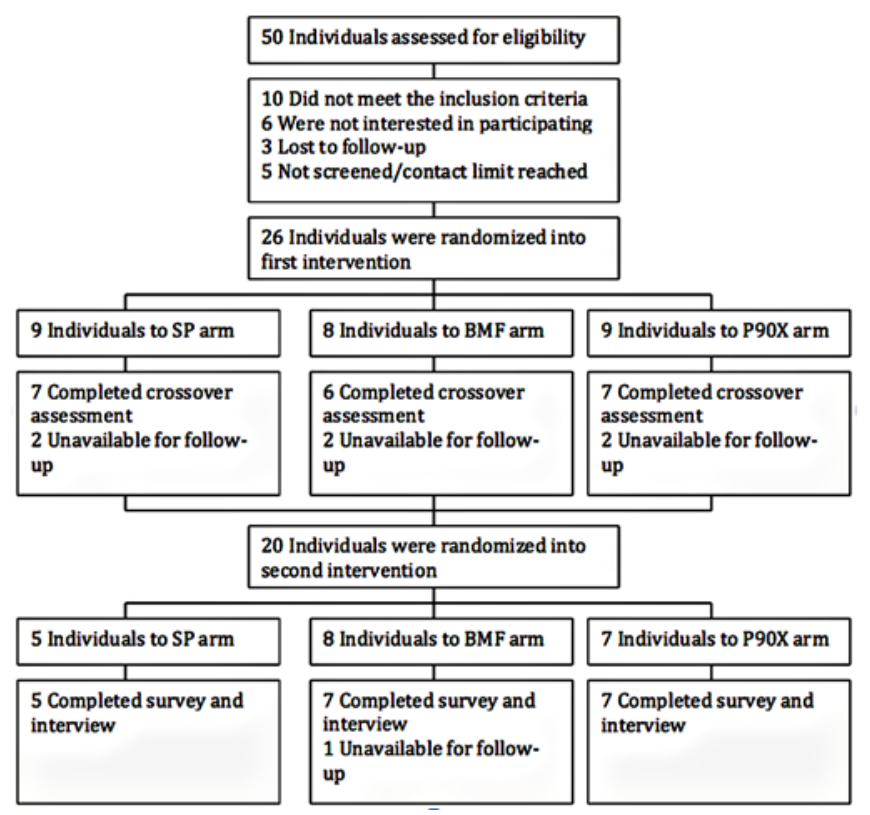

Figure 5.

Participant flowchart. BMF $=$ BodyMedia FIT, SP $=$ SparkPeople.

(53.3\%) of participants reported a service-connected disability. A majority of those participating (58\%) said they were an expert or advanced user of the Internet. Additionally, of the participants that had a cellular telephone (66.6\%), three-quarters used smartphones (75\%). Average BMI among study participants was $35.26 \pm 4.22$. None of the participants' self-reported excellent health. Reported levels of social support for both exercise and diet were relatively low. On average, participants lost $4.43 \mathrm{lb}$ ( $p=$ 0.01) using SparkPeople, $2.65 \mathrm{lb}(p=0.04)$ using the BodyMedia FIT, and $2.47 \mathrm{lb}(p=0.17)$ using the P90X DVDs.

\section{Qualitative Results}

Our qualitative analysis revealed five primary themes, including three that corresponded with the key components of the selected interventions: social support, objective monitoring, and structured activity. A fourth theme that emerged during the analysis process focused on issues related to awareness or understanding while the final theme was specific to the point-of-decision prompts.

\section{Online Social Support and Engagement}

In this study, social support was defined as the participant talking to others about diet and exercise as well as 
Table.

Baseline characteristics.

\begin{tabular}{|c|c|}
\hline Characteristic & Total \\
\hline \multicolumn{2}{|l|}{ Race, Frequency (\%) } \\
\hline American Indian & $1(4)$ \\
\hline Black & $4(17)$ \\
\hline Other & $1(4)$ \\
\hline White & $18(75)$ \\
\hline \multicolumn{2}{|l|}{ Military Branch, Frequency (\%) } \\
\hline Air Force & $2(8)$ \\
\hline Army & $16(67)$ \\
\hline Marine Corps & $1(4)$ \\
\hline Navy & $5(21)$ \\
\hline BMI (mean \pm SD) & $32.3 \pm 4.2$ \\
\hline \multicolumn{2}{|l|}{ Internet, Frequency (\%) } \\
\hline Expert & $3(13)$ \\
\hline Advanced & $11(46)$ \\
\hline Moderate & $9(38)$ \\
\hline Basic & $1(4)$ \\
\hline \multicolumn{2}{|l|}{ Social Support ${ }^{*}($ mean \pm SD) } \\
\hline Exercise & $2.14 \pm 0.49$ \\
\hline Diet & $2.60 \pm 0.70$ \\
\hline \multicolumn{2}{|l|}{ Health Status, Frequency (\%) } \\
\hline Excellent & 0 \\
\hline Very Good & $3(13)$ \\
\hline Good & $8(33)$ \\
\hline Fair & $11(46)$ \\
\hline Poor & $2(8)$ \\
\hline Number of Comorbidities & 3.5 \\
\hline $\operatorname{Pain}^{\dagger}($ mean \pm SD) & $3.6 \pm 2.2$ \\
\hline Depression $^{\ddagger}($ mean \pm SD) & $10.5 \pm 4.5$ \\
\hline \multicolumn{2}{|c|}{$\begin{array}{l}{ }^{*} \text { Scale: } 5 \text { = very often received support, } 1 \text { = received no suppo } \\
{ }^{\dagger} \text { Scale: } 0=\text { no pain, } 10=\text { as much pain as they can imagine. } \\
{ }^{\ddagger} \text { Center for Epidemiologic Studies Short Depression Scale. } \\
\text { BMI = body mass index, SD = standard deviation. }\end{array}$} \\
\hline
\end{tabular}

using the intervention's online community. All of the social support and engagement with online community forums happened through SparkPeople. While P90X has online community forums, none of the participants used the resource.

Women Veterans, in general, were more likely to use and engage with the online communities, especially if they felt they did not have a lot of outside support. As one woman stated, "It kept me motivated, it kept me very motivated to the point where I felt like I was part of the team." Another participant stated, "Just the community ... that really helped me. I've never really been involved in that sort of community before so that really motivated and helped me . . . because I really don't have that at home."
Many of the men thought that the social aspects of SparkPeople may have been geared more toward women users.

The majority of study participants were "lurkers," people who go on the Web site to read comments but do not participate or post in the discussion. For example, one participant stated, "I'm not necessarily a bloggy (sic) type of person, but there were a couple of discussion forums where I didn't have a problem going in and reading." Several participants stated they found much of the information on the social forums and other articles on the sites helpful: "I read a lot of the tips, they have the tips of the day. . . . I read that just about every day." One person mentioned SparkPeople on her Facebook status, thereby engaging the individual's own social network: "I've been advertising it all over Facebook. . . . [I post] 'Go to SparkPeople."” Also, at least one of the participants continued to use Sparkpeople even after the study was completed, saying, "I like SparkPeople. . . . I am still able to be in the groups."

\section{Objective Monitoring}

The only intervention with an objective monitoring function was the BodyMedia FIT device. Overall, the participants were satisfied with the device. However, while some participants indicated that the data provided were helpful, there seemed to be a lack of awareness about how to use the information to make healthy behavior changes. One participant stated he became more aware of his sleep, but he did not state how he planned to use that information. Additionally, some participants did not feel that the intervention was "strong" and said that the individual needs to be accountable for behavior change; the device simply tracks it. For example, one participant said, "If I wasn't a self-motivator to do an activity, it would just be keeping track of why I'm not losing weight." One participant stated that it was motivating to see his activity level, but he still did not necessarily change his behavior. However, for most, the mere presence of the device on the arm made them feel accountable for their actions; they knew they should watch what they eat or do more physical activities. As one participant said, "Just having it there and knowing it was there [made me feel accountable].” Other participants enjoyed the BodyMedia FIT device, saying that it was easy to use and track their activities. For example, a participant stated, "You put it on and forget about it." A couple subjects mentioned that the BodyMedia FIT device was helpful in maintaining their activity goals, as one subject noted: "I like having all of that information available to 
me about how I am doing during the day. I think it is a great tool and it is a great assessment and it's a great way to up your activity levels. . . . I would see that I only have 7,000 steps, and I'm like, 'Okay, I still need 1,000 more steps today' and then I would go out and do something.”

\section{Structure}

Most participants enrolled in this study had recently transitioned from active military service to civilian life and many noted that they had a need for some structure. One participant stated that in the military, someone was always telling them what physical training to do and they felt that they continued to need that structure. The P90X intervention was perceived by some of the participants to have the most structure: "I liked that it [P90X] was very structured. . . . It keeps you on task." However, this intense workout did cause some musculoskeletal injuries and pain, more specifically, an upper-back strain that was caused from doing one of the P90X exercises, foot pain after doing a few sessions of P90X, and a general awareness of how deconditioned they were since leaving the military.

\section{Awareness and Understanding}

Some of the participants who used the BodyMedia FIT device did not perceive the intervention to be strong enough regarding tracking their diet, but those that used the SparkPeople Web site stated that the food tracker was helpful. The participants that used the food tracker function and informational resources available in SparkPeople appeared able to make the link between what they ate and their weight. As one participant said, "It's a way to get useful information on cholesterol, lowering your cholesterol, lowering your fat, [it has] information on different topics.” Many participants logged their food intake on the paper logs provided by P90X but were not aware of the calories, fat, and carbohydrates in the foods. However, individuals in the SparkPeople intervention could log their foods directly on the Web site and see the calorie amounts, making it easier for many participants to see what changes they needed to make in their diet. As one participant described, "They [SparkPeople] say a portion size of French fries is like ten sticks and you're like 'I know I had more than ten.'” Although many understood that changing to healthier foods was the appropriate behavior, one participant continued to eat the same foods but reduced the portions.

BodyMedia FIT also had a food tracker that people could use with the system; however, many found it cum- bersome to use: "Cooking meals and trying to input exactly what I cooked or what I prepared was a downer. ... If I could not find what I cooked and how to input, it told me to enter the nutritional information that's on the package, but that would've been a whole lot of inputting or figuring out time, so I didn't do that.” Another participant stated, "You'd have a hard time finding certain things [foods]. So you had to spell it just so. I found that kind of annoying." However, participants using the BodyMedia FIT device who entered their food found this aspect to be very helpful, stating, "Seeing the calories, like actually realizing how much I consumed, had the biggest impact on me." Another said, "I was actually able to evaluate what it is that I'm putting into my body and start making the more health-conscience choices that I need to make."

\section{Point-of-Decision Prompts}

This study also provided the participants with several point-of-decision prompts to examine any effect on their eating or exercise behaviors. Overall, about half of the participants used at least one of the prompts during the interventions. The refrigerator prompt that encouraged people to eat a healthy snack or drink a glass of water appeared to be the most popular among the participants. Many of the subjects did not post all of the prompts or did not post them where the study team suggested. Some of the participants also thought the posters were unattractive and boring. Two participants mentioned that they put a poster near their computer (sleeping and walking). Two participants stated that they used the posters during the first intervention; however, by the second intervention the effectiveness of the poster seemed to decline.

\section{DISCUSSION}

This pilot study demonstrated high levels of satisfaction by the OIF/OEF Veteran participants with all of the low-cost, home-based, commercially available interventions. Participants lost weight with each strategy. Qualitative themes emphasized the value of all three of the mechanisms tested in the study but also brought to light some of the limitations of each approach. Identifying and understanding the experiences, use, and preferences of OIF/OEF Veterans with these various features is critical for developing and delivering effective programs to promote weight loss and healthier behaviors for this population. 
Social support was a key aspect for study participants. This included social support from other study participants as well as outside members (those who are on the Web site but not part of the study). This is consistent with other research that supports the importance of social support for improving exercise and nutrition $[11,26]$. However, while social support was found to be helpful among women participants, male participants did not socially interact on the site as much as the women but exhibited lurking behaviors (they would read posts, but not participate). This lurking behavior is common with many online communities or forums [27]. In addition, when the social support aspects of the intervention were not seamlessly integrated into the intervention, the participants did not use it. For example, the P90X program has a proprietary social network site that we informed the participants about, but none of them used it.

All of the interventions encouraged logging food and activities; however, each did it in a different way. Overall, the logging helped the participants become more aware of their behaviors, but this did not always lead to behavior change because some participants did not know what to do with the information. This suggests that the interventions that have people write down or simply log what they ate or activities that they performed do not have the same effect as applications, telephone or Webbased, that can provide some additional metadata such as calories, fat, and carbohydrate per serving. As was demonstrated in the BodyMedia FIT, some of the information the device provided was liked by the participants, but it did not provide courses of action for an individual to take to make healthy changes. It is possible that with a certain amount of coaching or counseling, this tool may have been more effective, which would be consistent with past literature [28-30]. In the future, these types of applications may be able to make real-time suggestions to individuals, which might further the strength of logging food and fitness activities.

All of the interventions provided some form of structure to help participants be more physically active or manage their diet. The video intervention provided the structure that was enjoyed among the participants. Perhaps these Web-based and monitor-based interventions could provide customized physical activity plans based on the current abilities of the individual. This information could then be linked to the food totals, thus providing the structure that is needed and comprehensive approach that was missing in all of the interventions.
In addition to identifying what were considered the most helpful features or key components of an intervention, this study also revealed some weaknesses or issues to be addressed to improve program use. For example, when the activities are not seamlessly integrated or a main focus of the intervention, the "secondary" parts or functions will go unused. For Web-based interventions, having a good design is extremely important. Participants in this study were provided handouts and directions to help them learn how to get around the Web sites. Once the participants were able to figure out how to navigate the sites, it became easier for them. As for the point-ofdecision prompts, their biggest weakness was their static nature or time the participants were desensitized to them. While past research has shown point-of-decision posters to be moderately effective in certain situations, the static nature of the signs has also been a barrier of use [21,31]. It appears that there is less fatigue with these posters in public settings than in a home environment where they would be seen more frequently.

As with all studies, there are some limitations to this research. First, our sample size was relatively small. There was a trend toward weight loss; however, the study had limited power to detect statistically significant change. By performing semistructured interviews with the participants, we were able to gain more insight into patient experiences with each of the interventions. Additionally, there were six dropouts from the study; while this is common for most intervention studies, it also points to the fact that even with convenient interventions, these Veterans have complex lives and multiple comorbidities that make it difficult for them to participate in these programs. There may have been some carryover effects from the first arm of the study to the second arm. However, having a random sequence for crossover allowed us to have the participants compare the interventions, which in the future will assist with better development and tailoring of approaches to promote physical activity and weight management for this population. Last, the length of the intervention was relatively short. We were unable to determine long-term effectiveness or adherence to any of the interventions.

\section{CONCLUSIONS}

Being obese or overweight has negative health consequences for all individuals; it is an especially difficult problem for Veterans, who are more likely to experience a 
myriad of other conditions. Combat Veterans that have recently returned from overseas tend to gain weight rapidly, and if the VA can help them maintain a healthy weight or lose weight, this can help prevent diabetes and coronary artery disease, thus helping Veterans achieve better health and quality of life and saving the VA millions of dollars $[2,5]$. This study demonstrated the potential feasibility of using relatively low-cost or free interventions to promote healthy lifestyles and weight loss among OIF/ OEF Veterans. This pilot study examined the satisfaction and feasibility of three interventions that focused on one of the following three mechanisms: (1) online mediated social support, (2) objective monitoring of physical activity, and (3) intensive structured workouts. The most successful intervention in terms of highest participant satisfaction and positive weight loss results was SparkPeople, which utilizes online social support. Many of the participants found the support provided online to be helpful and informative in their behavior change. This pilot study suggested that the objective monitoring device was not beneficial without some sort of interactive goal setting and coaching. Lastly, the primarily exercise-focused intervention was perceived to be too difficult for many of the participants and even caused some injuries but was appreciated for the intensity and structure it provided. The findings from this study provide important insights for developing and further testing of these mechanisms for assisting OIF/OEF Veterans with weight management and possibly other longer-term health benefits.

\section{ACKNOWLEDGMENTS}

\author{
Author Contributions: \\ Research design: B. Holtz, C. R. Richardson, S. L. Krein, \\ N. D. Giardino. \\ Acquisition of data: D. R. Bentley, M. E. Hughes. \\ Analysis and interpretation of data: B. Holtz, C. R. Richardson, \\ D. R. Bentley, M. E. Hughes. \\ Drafting of manuscript: B. Holtz, C. R. Richardson, S. L. Krein. \\ Critical revision of manuscript for important intellectual content: \\ B. Holtz, C. R. Richardson.
}

Financial Disclosures: The authors have declared that no competing interests exist.

Funding/Support: This material was based on work supported by the VA Ann Arbor Center for Clinical Management Research and the VA Diabetes Quality Enhancement Research Initiative Research Coordinating Center (grant DIB 98-001).

Additional Contributions: Dr. Holtz is now with the Department of Telecommunications, Information Studies, and Media, Michigan State University, East Lansing, Michigan.
Institutional Review: This research was approved by the VA Ann Arbor Healthcare System Institutional Review Board with written informed consent provided by all participants.

Participant Follow-Up: The authors do not plan to inform participants of the publication of this study.

Disclaimer: The views expressed in this article are those of the authors and do not necessarily reflect the position or policy of the VA or U.S. Government.

\section{REFERENCES}

1. CDC. Obesity: Halting the epidemic by making health easier [Internet]. Atlanta (GA): Centers for Disease Control and Prevention; 2011 [cited 2012 May 30]. Available from: http://www.cdc.gov/chronicdisease/resources/publications/ AAG/obesity.htm

2. Koepsell TD, Littman AJ, Forsberg CW. Obesity, overweight, and their life course trajectories in veterans and non-veterans. Obesity (Silver Spring). 2012;20(2):434-39. [PMID:21293452] http://dx.doi.org/10.1038/oby.2011.2

3. Littman AJ, Forsberg CW, Koepsell TD. Physical activity in a national sample of veterans. Med Sci Sports Exerc. 2009;41(5):1006-13. [PMID:19346987] http://dx.doi.org/10.1249/MSS.0b013e3181943826

4. Das SR, Kinsinger LS, Yancy WS Jr, Wang A, Ciesco E, Burdick M, Yevich SJ. Obesity prevalence among veterans at Veterans Affairs medical facilities. Am J Prev Med. 2005;28(3):291-94. [PMID:15766618] http://dx.doi.org/10.1016/j.amepre.2004.12.007

5. Nelson KM. The burden of obesity among a national probability sample of veterans. J Gen Intern Med. 2006;21(9): 915-19. [PMID:16918734] http://dx.doi.org/10.1007/BF02743137

6. Buis LR, Kotagal LV, Porcari CE, Rauch SA, Krein SL, Richardson CR. Physical activity in postdeployment Operation Iraqi Freedom/Operation Enduring Freedom veterans using Department of Veterans Affairs services. J Rehabil Res Dev. 2011;48(8):901-11. [PMID:22068369] http://dx.doi.org/10.1682/JRRD.2010.08.0144

7. Department of Veterans Affairs. Managing overweight and/ or obesity for veterans everywhere (MOVE!) program [Internet]. Washington (DC): Department of Veterans Affairs; 2006 [cited 2013 June 17]. Available from:

http://www.move.va.gov/download/Resources/ 1101.1HK3 27 06.pdf

8. Hwang KO, Ottenbacher AJ, Green AP, Cannon-Diehl MR, Richardson O, Bernstam EV, Thomas EJ. Social support in an Internet weight loss community. Int $\mathrm{J}$ Med Inform. 2010;79(1):5-13. [PMID:19945338] http://dx.doi.org/10.1016/j.ijmedinf.2009.10.003 
9. Hwang KO, Etchegaray JM, Sciamanna CN, Bernstam EV, Thomas EJ. Structural social support predicts functional social support in an online weight loss programme. Health Expect. 2012 Jan 2. Epub ahead of print. [PMID:22212418]

10. Johnson F, Wardle J. The association between weight loss and engagement with a web-based food and exercise diary in a commercial weight loss programme: A retrospective analysis. Int J Behav Nutr Phys Act. 2011;8:83.

[PMID:21810222]

http://dx.doi.org/10.1186/1479-5868-8-83

11. Richardson CR, Buis LR, Janney AW, Goodrich DE, Sen A, Hess ML, Mehari KS, Fortlage LA, Resnick PJ, Zikmund-Fisher BJ, Strecher VJ, Piette JD. An online community improves adherence in an internet-mediated walking program. Part 1: Results of a randomized controlled trial. J Med Internet Res. 2010;12(4):e71. [PMID:21169160] http://dx.doi.org/10.2196/jmir.1338

12. Carr LJ, Bartee RT, Dorozynski C, Broomfield JF, Smith ML, Smith DT. Internet-delivered behavior change program increases physical activity and improves cardiometabolic disease risk factors in sedentary adults: Results of a randomized controlled trial. Prev Med. 2008;46(5):431-38. [PMID:18207228]

http://dx.doi.org/10.1016/j.ypmed.2007.12.005

13. Hurling R, Catt M, Boni MD, Fairley BW, Hurst T, Murray P, Richardson A, Sodhi JS. Using internet and mobile phone technology to deliver an automated physical activity program: Randomized controlled trial. J Med Internet Res. 2007;9(2):e7. [PMID:17478409]

http://dx.doi.org/10.2196/jmir.9.2.e7

14. Laplante C, Peng W. A systematic review of e-health interventions for physical activity: An analysis of study design, intervention characteristics, and outcomes. Telemed J E Health. 2011;17(7):509-23. [PMID:21718092]

http://dx.doi.org/10.1089/tmj.2011.0013

15. Marcus BH, Lewis BA, Williams DM, Dunsiger S, Jakicic JM, Whiteley JA, Albrecht AE, Napolitano MA, Bock BC, Tate DF, Sciamanna CN, Parisi AF. A comparison of Internet and print-based physical activity interventions. Arch Intern Med. 2007;167(9):944-49. [PMID:17502536] http://dx.doi.org/10.1001/archinte.167.9.944

16. Wanner M, Martin-Diener E, Braun-Fahrländer C, Bauer G, Martin BW. Effectiveness of active-online, an individually tailored physical activity intervention, in a real-life setting: Randomized controlled trial. J Med Internet Res. 2009; 11(3):e23. [PMID:19666456] http://dx.doi.org/10.2196/jmir.1179

17. Pellegrini CA, Verba SD, Otto AD, Helsel DL, Davis KK, Jakicic JM. The comparison of a technology-based system and an in-person behavioral weight loss intervention. Obe- sity (Silver Spring). 2012;20(2):356-63. [PMID:21311506] http://dx.doi.org/10.1038/oby.2011.13

18. Richardson CR, Newton TL, Abraham JJ, Sen A, Jimbo M, Swartz AM. A meta-analysis of pedometer-based walking interventions and weight loss. Ann Fam Med. 2008;6(1): 69-77. [PMID:18195317]

http://dx.doi.org/10.1370/afm.761

19. Asztalos M, De Bourdeaudhuij I, Cardon G. The relationship between physical activity and mental health varies across activity intensity levels and dimensions of mental health among women and men. Public Health Nutr. 2010; 13(8):1207-14. [PMID:20018121] http://dx.doi.org/10.1017/S1368980009992825

20. Nybo L, Sundstrup E, Jakobsen MD, Mohr M, Hornstrup T, Simonsen L, Bülow J, Randers MB, Nielsen JJ, Aagaard P, Krustrup P. High-intensity training versus traditional exercise interventions for promoting health. Med Sci Sports Exerc. 2010;42(10):1951-58. [PMID:20195181] http://dx.doi.org/10.1249/MSS.0b013e3181d99203

21. Kwak L, Kremers SP, van Baak MA, Brug J. A posterbased intervention to promote stair use in blue- and whitecollar worksites. Prev Med. 2007;45(2-3):177-81.

[PMID:17610944]

http://dx.doi.org/10.1016/j.ypmed.2007.05.005

22. Sallis JF, Grossman RM, Pinski RB, Patterson TL, Nader PR. The development of scales to measure social support for diet and exercise behaviors. Prev Med. 1987;16(6): 825-36. [PMID:3432232] http://dx.doi.org/10.1016/0091-7435(87)90022-3

23. Ware J Jr, Kosinski M, Keller SD. A 12-Item Short-Form Health Survey: Construction of scales and preliminary tests of reliability and validity. Med Care. 1996;34(3):220-33. [PMID:8628042] http://dx.doi.org/10.1097/00005650-199603000-00003

24. Krebs EE, Lorenz KA, Bair MJ, Damush TM, Wu J, Sutherland JM, Asch SM, Kroenke K. Development and initial validation of the PEG, a three-item scale assessing pain intensity and interference. J Gen Intern Med. 2009; 24(6):733-38. [PMID:19418100] http://dx.doi.org/10.1007/s11606-009-0981-1

25. Radloff L. CES-D scale: A self report depression scale for research in the general populations. Appl Psychol Meas. 1977;1(3):385-401.

http://dx.doi.org/10.1177/014662167700100306

26. Resnick PJ, Janney AW, Buis LR, Richardson CR. Adding an online community to an internet-mediated walking program. Part 2: Strategies for encouraging community participation. J Med Intern Res. 2010;12(4):e72.

[PMID:21169161]

http://dx.doi.org/10.2196/jmir.1339

27. Lampe C, Wash R, Velasquez A, Ozkaya E. Motivations to participate in online communities. Proceeding of the 29th 
International Conference on Human Factors in Computing Systems; 2010 Apr 10-15; Atlanta, GA.

28. Barry VW, McClain AC, Shuger S, Sui X, Hardin JW, Hand GA, Wilcox S, Blair SN. Using a technology-based intervention to promote weight loss in sedentary overweight or obese adults: A randomized controlled trial study design. Diabetes Metab Syndr Obes. 2011;4:67-77.

[PMID:21448324]

http://dx.doi.org/10.2147/DMSO.S14526

29. Shuger SL, Barry VW, Sui X, McClain AC, Hand GA, Wilcox S, Meriwether RA, Hardin JW, Blair SN. Electronic feedback in a diet- and physical activity-based lifestyle intervention for weight loss: A randomized controlled trial. Int J Behav Nutr Phys Act. 2011;8:41.

[PMID:21592351]

http://dx.doi.org/10.1186/1479-5868-8-41

30. Sieverdes JC, Sui X, Hand GA, Barry VW, Wilcox S, Meriwether RA, Hardin JW, McClain AC, Blair SN. Cardiometabolic results from an armband-based weight loss trial. Diabetes Metab Syndr Obes. 2011;4:187-94.

[PMID:21760735]

http://dx.doi.org/10.2147/DMSO.S18649

31. Badland HM, Schofield GM. Posters in a sample of professional worksites have no effect on objectively measured physical activity. Health Promot J Austr. 2005;16(1):78-81. [PMID:16389937]

Submitted for publication April 9, 2013. Accepted in revised form July 11, 2013.

This article and any supplementary material should be cited as follows:

Holtz B, Krein SL, Bentley DR, Hughes ME, Giardino ND, Richardson CR. Comparison of Veteran experiences of low-cost, home-based diet and exercise interventions. J Rehabil Res Dev. 2014;51(1):149-60.

http://dx.doi.org/10.1682/JRRD.2013.04.0088

ResearcherID/ORCID: Bree Holtz, PhD: B-9371-2014; Caroline R. Richardson, MD: A-9237-2009

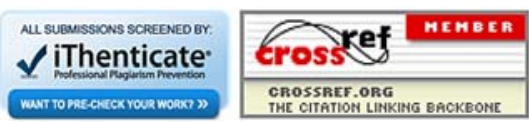

